\title{
Estudo de inteligibilidade da fala com apoio visual de animação facial em crianças com dislexia do desenvolvimento.
}

Keila Alessandra B. Knobel (PQ), Daniella Priscila F. Batista (IC).

\section{Resumo}

O objetivo do estudo foi verificar o desempenho de crianças disléxicas e não disléxicas no processamento das informações visuais e auditivas em um sistema de animação facial 2D. As crianças disléxicas, quando comparadas ao grupo controle, são menos capazes de lidar com as imperfeições de um modelo articulatório de animação facial sintético.

Palavras Chave: dislexia, animação facial, inteligibidade de fala.

\section{Introdução}

A dislexia caracteriza-se como uma deficiência específica de habilidades de leitura, na qual o desempenho do estudante é abaixo do esperado em relação à sua idade cronológica, ao potencial intelectual e ao seu nível escolar (DSM-5, 2013), e pode estar associada a déficits no processamento fonológico dos sons da fala (SNOWLING, 2013).

Este estudo tem como objetivo verificar o desempenho de crianças com e sem dislexia no processamento das informações visuais e auditivas em um modelo articulatório simplificado de um sistema de animação facial 2D. Foram avaliadas 13 crianças disléxicas e 26 crianças não disléxicas, todas na faixa etária dos 9 aos 15 anos. Para tanto, usamos um software que apresenta 27 logatomas (palavras sem sentido) de forma aleatória em oito etapas de avaliação, também aleatórias: (1) áudio sem ruído; (2) áudio com ruído $(\mathrm{SNR}=-12 \mathrm{~dB}$ ); (3) vídeo acompanhado de áudio sem ruído; (4) vídeo acompanhado de áudio com ruído $(\mathrm{SNR}=-12 \mathrm{~dB})$; (5) vídeo sem áudio; (6) animação acompanhada de áudio sem ruído; (7) animação acompanhada de áudio com ruído ( $S N R=-12 \mathrm{~dB})$ e (8) animação sem áudio.

\section{Resultados e Discussão}

Em média, o grupo de disléxicos apresentou um pior nível de inteligibilidade de fala para todos os estímulos em comparação ao grupo controle. Nos dois grupos, houve melhor desempenho de inteligibilidade da fala com apoio do canal visual (vídeo real e animação facial) durante as apresentações de áudio com ruído. Porém, nas etapas de animação facial, os dois grupos foram piores em comparação ao modelo de vídeo real. O impacto da simplificação dos movimentos articulatórios da fala impostas pelo modelo visual de animação facial parece ser maior para as crianças disléxicas. Quando comparadas ao grupo controle parecem ser menos capazes de lidar com as imperfeições de um modelo articulatório de animação facial.

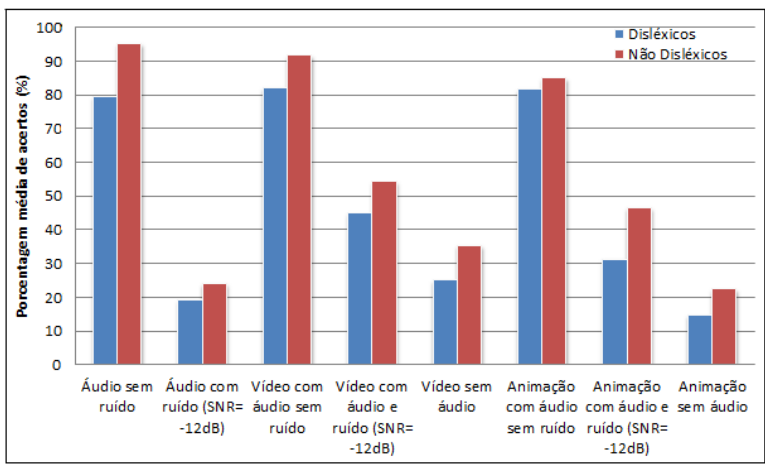

Figura 1: Comparação de respostas para os dois grupos em cada etapa de avaliação.

\section{Conclusões}

A redução de informações visuais fonoarticulatórias dificulta a inteligibilidade de fala para crianças disléxicas. Tal resultado incentiva novos estudos para verificar a hipótese de que um programa de treinamento utilizando estímulos de animação facial poderia melhorar as capacidades funcionais dos jovens disléxicos.

\section{Agradecimentos}

As autoras agradecem à equipe de pesquisadores envolvidos: Dra. Paula D. P. Costa, Fga. Dra. Cíntia A. Salgado Azoni, Profo Dr. José Mário de Martino; aos participantes e o Conselho Nacional de Desenvolvimento Científico e Tecnológico (CNPq) pelo apoio financeiro para a presente pesquisa.

P. Association et al., Diagnostic and statistical manual of mental disorders. DSM-5. American Psychiatric Association, 2013.

SNOWLING, M.J. Early identification and interventions for dyslexia: a contemporary view, JORSEN, v. 13, n. 1, p. 1471-3802, 2013. 